\title{
The median effective dose (ED50) of cis- Atracurium for laryngeal mask airway insertion during general Anaesthesia for patients undergoing urinary surgery
}

Xiaohua Wang ${ }^{1,2,3^{*}}$, Ke Huang ${ }^{1,2,3}$, Hao Yan ${ }^{4}$, Fei Lan ${ }^{1,2,3}$, Dongxu Yao ${ }^{1,2,3}$, Yanhong Li Li,2,3, Jixiu Xue $^{1,2,3}$ and Tianlong Wang ${ }^{1,2,3^{*}}$

\begin{abstract}
Background: In clinical practice, the laryngeal mask airway is an easy-to-use supraglottic airway device. However, the cis-atracurium dosage for laryngeal mask insertion has not been standardised. We aimed to determine the optimal dose of cis-atracurium using a sequential method for successful laryngeal mask insertion.
\end{abstract}

Methods: The cohort study protocol is registered at clinicaltrial.gov (NCT-03668262). Twenty-three patients undergoing elective urinary surgery were sequentially administered cis-atracurium doses as follows: 150, 100, 70, 50, 30 , and $20 \mathrm{\mu g} \mathrm{kg}^{-1}$. The main outcome involved the determination of the response to laryngeal mask airway insertion: $\geq 16$ points and $<16$ points indicated "satisfactory" and "unsatisfactory" responses, respectively. The median effective dose was estimated using the mean of the seven crossovers from "satisfactory" and "unsatisfactory" responses. The primary outcome involved the determination of the median effective dose (ED50) of cis-atracurium for laryngeal mask airway insertion.

Results: The median effective dose of cis-atracurium was $26.5 \mu \mathrm{g} \cdot \mathrm{kg}^{-1}$ (95\% Cl 23.6-29.8) using the sequential method. Heart rate was decreased in the $50 \mu \mathrm{g} \cdot \mathrm{kg}^{-1}$ group compared to that in the $30 \mu \mathrm{g} \cdot \mathrm{kg}^{-1}$ group at timepoints $\mathrm{T7}$, T8, and $\mathrm{T} 10(P=0.0482, P=0.0460$, and $P=0.0236$, respectively), but no difference was observed in the $20 \mu \mathrm{g} \cdot \mathrm{kg}^{-1}$ group. Systolic blood pressure was decreased in the $50 \mu \mathrm{g} \cdot \mathrm{kg}^{-1}$ group compared to that in the $20 \mu \mathrm{g}^{\mathrm{kg}}{ }^{-1}$ group at timepoints T2, T3, and T4 ( $P=0.0159, P=0.0233$, and $P=0.0428$, respectively). The train-of-four value was significantly lower in the $50 \mu \mathrm{g} \cdot \mathrm{kg}^{-1}$ group than in the $30 \mu \mathrm{g} \cdot \mathrm{kg}^{-1}$ group at timepoint T3 $(P=0.0326)$.

Conclusions: The ED50 of cis-atracurium was $26.5 \mu \mathrm{g} \cdot \mathrm{kg}^{-1}$ for laryngeal mask airway insertion.

Trial registration: Clinicaltrial.gov Registry, NCT03668262, Registered on 11 September 2018.

Keywords: Sequential method, ED50, cis-Atracurium, Urinary surgery, Laryngeal mask

\footnotetext{
*Correspondence: 15910851623@163.com; w_t15595@yahoo.com
}

'Department of Anesthesiology, Xuanwu Hospital, Capital Medical University, Beijing 100053, China

Full list of author information is available at the end of the article

(c) The Author(s). 2020 Open Access This article is licensed under a Creative Commons Attribution 4.0 International License, which permits use, sharing, adaptation, distribution and reproduction in any medium or format, as long as you give appropriate credit to the original author(s) and the source, provide a link to the Creative Commons licence, and indicate if changes were made. The images or other third party material in this article are included in the article's Creative Commons licence, unless indicated otherwise in a credit line to the material. If material is not included in the article's Creative Commons licence and your intended use is not permitted by statutory regulation or exceeds the permitted use, you will need to obtain permission directly from the copyright holder. To view a copy of this licence, visit http://creativecommons.org/licenses/by/4.0/ The Creative Commons Public Domain Dedication waiver (http://creativecommons.org/publicdomain/zero/1.0/) applies to the data made available in this article, unless otherwise stated in a credit line to the data. 


\section{Background}

The laryngeal mask airway (LMA) is a supraglottic ventilation device that is more effective than mask airway for difficult airway management and includes the characteristics of mask and endotracheal intubation [1]. LMA insertion has more advantages than endotracheal intubation: it has little influence on the patient's circulation during insertion, reduces the dosage of analgesics required to maintain anaesthesia during surgery, and is well-tolerated [2]. Therefore, the laryngeal mask is widely used in elective minor surgery, particularly in minor urinary surgery [3]. The use of muscle relaxants is necessary to improve the conditions of laryngeal mask insertion [4]. Without muscle relaxants, the pharyngeal tissues are not relaxed, and appropriate laryngeal mask placement is difficult owing to resistance to mouth opening and biting [5]. Moreover, muscle relaxation is needed to avoid excessive airway reactivity of laryngeal mask insertion (e.g., laryngeal spasm, hypersalivation, coughing), to reduce laryngeal mask insertion-related complications (e.g., postoperative throat pain), and to reduce the incidence of airway complications such as hypoxia, ineffective ventilation, and sternal muscle stiffness that are induced by opioid analgesics [6-8]. Analgesic and narcotic agents are required in high dosages without the use of muscle relaxants, and an overdose of analgesic agents can inhibit the patient's haemodynamics [9]. Small doses of neuromuscular blocking agents (NMBAs) may improve mandibular relaxation and shorten the time required for laryngeal mask placement, thereby improving the laryngeal mask placement conditions [10].

Cis-atracurium is a non-depolarizing NMBA and has been widely used adjunctively during anaesthesia to facilitate endotracheal intubation and provide a longer duration of muscle relaxation [11]. It is spontaneously degraded at physiological $\mathrm{pH}$ via Hofmann elimination, which is an organ-independent degradative mechanism that yields laudanosine and plasma esterase-mediated hydrolysis [12]. Little or no risk is associated with the use of cis-atracurium in patients with renal diseases; therefore, it is frequently used in general anaesthesia during urinary surgery. Furthermore, cis-atracurium has unique advantages and is approximately three times more potent than atracurium as a muscle relaxant [13]. It has less propensity to induce histamine release, which causes subsequent cutaneous flushing, hypotension, and tachycardia complications [14], and it significantly reduces the use of proinflammatory markers during surgery [15]. However, an overdose of cis-atracurium may increase the risk of aspiration, airway obstruction, and delayed recovery. The dosages of muscle relaxants used in trachea intubation vary greatly and range from 10 to $200 \mu \mathrm{g} \cdot \mathrm{kg}^{-1}$ [16-19]. However, a reasonable dosage of cis-atracurium under LMA has not been reported.
This study aimed to determine the median effective dose (ED50) of cis-atracurium for laryngeal mask insertion in anesthetised adults using Dixon's up-and-down method [20] and to determine the dose-response curves for laryngeal mask insertion in urinary surgery.

\section{Methods \\ Patient characteristics}

This prospective observational study was approved by the university's institutional review board (IRB no.: CINI-AD-20180808). All individuals participating in the trial provided written informed consent. The trial is also registered at http://ClinicalTrials.gov (registry no.: NCT03668262; date of registration: September 11, 2018). The methodology in this study followed the international guidelines for observational studies according to the Strengthening the Reporting of Observational Studies in Epidemiology (STROBE) 2010 statement (Supplementary-STROBE checklist). We recruited 23 prospective consecutive patients who were scheduled for elective minor urological surgery under general anaesthesia between 15 September, 2018, and 30 January, 2019, at Xuanwu Hospital (Beijing, China). All patients met the criteria for the American Society of Anesthesiologists (ASA) Physical Status I-III; Body Mass Index (BMI), $18.5-30 \mathrm{~kg} / \mathrm{m}^{2}$; age, 20-60 years; predicted operation duration < $180 \mathrm{~min}$; and estimated blood loss $<5 \mathrm{ml} \cdot \mathrm{kg}^{-}$

1 . The exclusion criteria were as follows: neuromuscular diseases; metabolic diseases; preoperative condition complicated with electrolyte disorders, serious hepatic insufficiency (i.e., liver transaminase level $>40 \mathrm{U} \cdot \mathrm{L}^{-1}$ ), or renal insufficiency (i.e., serum creatinine level $>1.2$ $\left.\mathrm{mg} \cdot \mathrm{dL}^{-1}\right)$; serious heart and lung disease; predicted difficult airway; use of preoperative medications that interact with non-depolarising NMBAs (e.g., aminoglycosides, polymyxin, steroids, phenytoin sodium, neuroleptics, carbamazepine); history of allergy to NMBAs; and history of alcoholism or drug abuse.

\section{Anaesthesia protocol}

After the patient entered the operating room, lactate Ringer's solution was infused at a rate of $5 \mathrm{ml} \cdot \mathrm{kg}^{-1} \cdot \mathrm{h}^{-1}$. After 3 min of oxygen supplied via the mask, intravenous sufentanil (dose, $0.25 \mu \mathrm{g} \cdot \mathrm{kg}^{-1}$; injection time, $30 \mathrm{~s}$ ) and etomidate (dose, $0.2 \mathrm{mg} \cdot \mathrm{kg}^{-1}$; injection time, $30 \mathrm{~s}$ ) were administered. The bispectral index (BIS) reaching a value below 60 and loss of the eyelash reflex indicated that the patient had lost consciousness, and the train-of-four (TOF) value was calibrated. The calibration of TOF as the baseline was 100. After calibration, cis-atracurium was administered (injection time, $5 \mathrm{~s}$ ). Three minutes after the cis-atracurium injection, and once the BIS reached a value of 40-60, an experienced anaesthesiologist placed a flexible LMA (Teleflex Medical, Wayne, 
PA, USA; Athlone Co., Westmeath, Ireland) of the appropriate type $\left(\mathrm{LMA}^{\circ}\right.$ Flexible criteria: $30-50 \mathrm{~kg}$ for No. 3; 50-70 kg for No. 4; and 70-100 kg for No. 5). The patients' responses were jointly evaluated by another anaesthesiologist who was blinded to the cis-atracurium concentrations when the LMA was inserted. The tidal volume setting was $7 \mathrm{ml} \cdot \mathrm{kg}^{-1}$, and the respiration rate setting was $12 \mathrm{RR} \cdot \mathrm{min}^{-1}$. If laryngeal mask insertion was unsuccessful, anaesthesia was deepened with further increments of cis-atracurium, or an inhalation agent, or both, until the laryngeal mask was tolerated; however, the patient was placed in the "unsatisfactory" group in these cases. Propofol combined with remifentanil was used to maintain the BIS at 40-60 throughout the operation. The range of blood pressure and heart rate (HR) fluctuation did not exceed the $20 \%$ baseline value. Body temperature was maintained at $>36^{\circ} \mathrm{C}$ using a warm air blanket.

\section{Cis-Atracurium administration and evaluation of the LMA placement conditions \\ Administration of cis-Atracurium and subdivision of groups}

The first patient enrolled in the study was exposed to an initial cis-atracurium concentration of $0.15 \mathrm{mg} \cdot \mathrm{kg}^{-1}$. The step size of the concentration was calculated by a common ratio 1.5; thus, the administered doses were $0.1=[0.15 /(1.5)], 0.06667=\left[0.15 /(1.5)^{2}\right], 0.04444=[0.15 /$ $\left.(1.5)^{3}\right], \quad 20 \mu \mathrm{g} \cdot \mathrm{kg}^{-1} \quad 962=\left[0.15 /(1.5)^{4}\right], \quad$ and $0.01975=\left[0.15 /(1.5)^{5}\right] \mathrm{mg}$. In the clinical setting, the actual administered doses were $0.15,0.1,0.07,0.05,0.03$, and $0.02 \mathrm{mg} \mathrm{kg}^{-1}$, which are equal to $150,100,70,50$, 30 , and $20 \mu \mathrm{g} \cdot \mathrm{kg}^{-1}$ in this study. We categorized the patients into six groups as follows: $150 \mu \mathrm{g} \cdot \mathrm{kg}^{-1}$ group, $100 \mu \mathrm{g} \cdot \mathrm{kg}^{-} 1$ group, $70 \mu \mathrm{g} \cdot \mathrm{kg}^{-} 1$ group, $50 \mu \mathrm{g} \cdot \mathrm{kg}^{-1}$ group, $30 \mu \mathrm{g} \cdot \mathrm{kg}^{-1}$ group, and $20 \mu \mathrm{g} \cdot \mathrm{kg}^{-1}$ group. Depending on the previous patient's response to the laryngeal mask, using a modified Dixon's up-and-down method, we adjusted the subsequent dose in the remaining patients [20]. Beginning with the first case of unsatisfactory response, the number of observation units was counted. A "satisfactory-satisfactory" response was noted at seven exchange points. This marked the completion of the test (Fig. 1). When self-contained respiration occurred during the operation, additional doses of cis-atracurium were re-administered to the patient.

\section{Laryngeal mask placement conditions}

The insertion condition was evaluated only when the laryngeal mask was inserted the first time. Using the recognised six-point-three scale proposed by Sivalingam [21], which has been used successfully in previous research, the following were graded: resistance to mouth opening, resistance to insertion, coughing, swallowing, laryngospasm/airway obstruction (including Paw pressure more than $40 \mathrm{mmHg}$ after insertion immediately), and head and body movement. Each item was scored 3 points, 2 points, and 1 point, based on the severity. A full score was 18 points. A score of $\geq 16$ points was

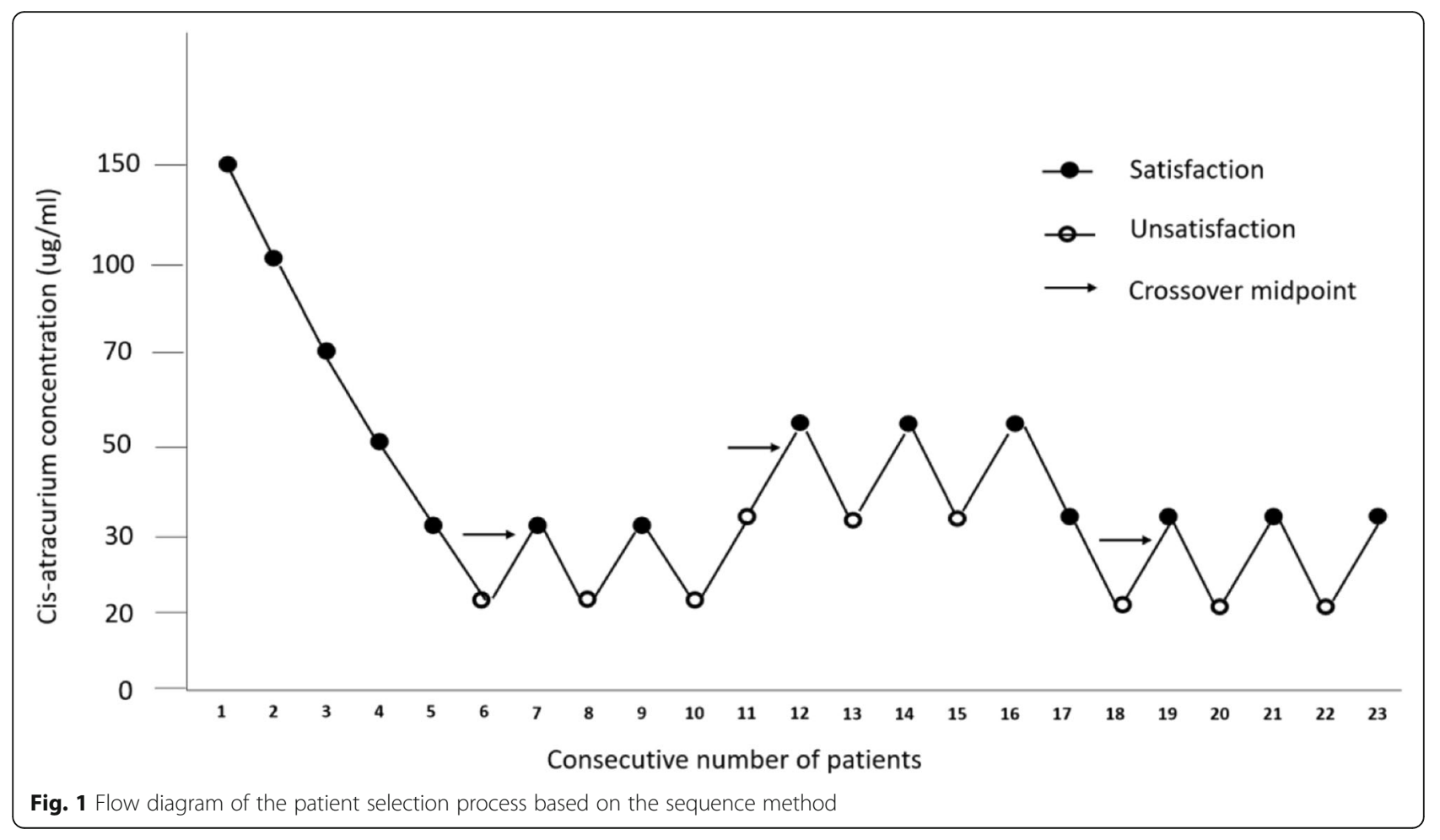


considered to be a "satisfactory" response, and a score of $<16$ points was considered to be an "unsatisfactory" response (Supplementary) (Table_S1). If the response was "unsatisfactory", the cis-atracurium dosagr was increased in the next patient. After approximately $60 \mathrm{~s}$ of successful laryngeal mask insertion, the position and ventilation condition of the laryngeal mask and whether the patient had a "satisfactory" or "unsatisfactory" response were recorded.

\section{Muscle relaxation (TOF) monitoring, general parameter monitoring, and blood sample analysis}

The patient's upper limb was extended and fixed. After degreasing the skin with alcohol, surface electrodes were placed on the side of the ulnar nerve of the wrist for TOF stimulation monitoring (TOF-Watch; Organon Ireland, Ltd., Swords, Dublin, Ireland). The sensor probe of the TOF monitor was placed between the thumb and forefinger with no resistance between them. When the patient lost consciousness, the calibration scale of $\mathrm{T} 1$ was 100 , the stimulation current was $45-75 \mathrm{~mA}$, the interval was $5 \mathrm{~s}$, and the frequency was $2 \mathrm{~Hz}$. The nasopharyngeal temperatures, electrocardiography, blood pressure, $\mathrm{HR}$, pulse oxygen saturation $\left(\mathrm{SpO}_{2}\right)$, and $\mathrm{BIS}$ of patients were routinely monitored. We set 10 timepoints to record variations during the operation as follows: upon administration of cis-atracurium (T1), and 3 min (i.e., at LMA insertion) (T2), $10 \mathrm{~min}$ (at the beginning of the operation) (T3), $20 \mathrm{~min}$ (T4), $30 \mathrm{~min}$ (T5), $40 \mathrm{~min}$ (T6), $50 \mathrm{~min}$ (T7), $60 \mathrm{~min}$ (T8), $70 \mathrm{~min}$ (T9), and 80 min after the administration of cis-atracurium (T10). Systolic blood pressure (SBP), diastolic blood pressure (DBP), $\mathrm{HR}, \mathrm{SpO}_{2}, \mathrm{BIS}, \mathrm{TOF}$ and airway peak pressure (Paw peak pressure) were recorded at each timepoint. Intraoperative haemodynamic changes and adverse reactions such as cough, respiratory depression, dizziness, nausea, and vomiting were also recorded.

\section{Statistical analysis}

The ED50 of cis-atracurium was determined by calculating the midpoint concentration of the crossover point from the "satisfactory" or "unsatisfactory" responses. To facilitate the dose-response analysis, the laryngeal mask insertion conditions were recorded as dichotomous outcomes. A probit analysis linear regression plot of the log dose versus the percentage response was generated, and interpolation (with 95\% CIs) was used to determine the laryngeal mask condition. The average of the midpoints of all pairs was used to calculate the ED50 using Dixon's up-and-down method. The number of responders at each dose was used to plot a sigmoid dose-response curve and a log-dose probit response relation. The other parameters were analysed using repeated measures ANOVA. The patient characteristics are presented as the mean $( \pm \mathrm{SD})$ or the number (proportion). A $P$-value of $<0.05$ was considered to represent significant difference among outcomes. These data were analysed using SPSS version 17.0 (SPSS Inc., Chicago, IL, USA). The sample size of 23 patients was based on $\alpha=0.05$ for the two-sided chi-square test to analyse trends in proportions and a logistic model of $\beta=0.1$ to detect the insertion success rates. The sample size of this study also was based on the fact that a minimum of seven independent pairs of participants exhibited a crossover point from a "satisfactory" response to an "unsatisfactory" response. In similar studies in the field of airway device insertion, the number of crossover points varied from six to eight, with six crossover points being the most common. For this study, seven crossovers were sufficient to determine the ED50 of cis-atracurium required to insert a laryngeal mask. A minimum of seven pairs of failure-success was required for the statistical analysis. The total score for the insertion conditions was calculated by addition. A score of $\geq 16$ represented the optimal condition for LMA insertion.

\section{Results}

Patient profile, Haemodynamics, TOF value, and ventilation condition for each dosage

Age, sex, weight, height, BMI, and the ASA Physical Status were similar among the three groups (Table 1). No significant differences were noted in the $\mathrm{pH}$ values and nasopharyngeal temperatures in all patients. Haemoglobin values, globulin fraction of plasma protein, and albumin fraction of plasma protein were similar among the groups (Table 1). The preoperative Mallampati variable did not differ among the groups. The operation duration, anaesthesia duration, and blood loss were nonsignificantly different among groups (Table 1). There was no statistical difference in the DBP among groups. The SBP was significantly decreased in the $20 \mu \mathrm{g} \cdot \mathrm{kg}^{-1}$ group compared with the $50 \mu \mathrm{g} \cdot \mathrm{kg}^{-1}$ group at T2, T3, and T4 $(P=0.0159, P=0.0233$, and $P=0.0428$, respectively; Fig. $2 \mathrm{a}$ and b). For each group, the HR did not significantly differ at most timepoints; however, the HR was significantly decreased at T7, T8, and T10 in the $50 \mu \mathrm{g} \cdot \mathrm{kg}^{-1}$ group compared to the $30 \mu \mathrm{g} \cdot \mathrm{kg}^{-1}$ group $(P=0.0482, P=0.0460$, and $P=0.0236$, respectively). This finding indirectly reflected the lower stress at these timepoints (Fig. 2c).

The BIS value did not significantly differ among the three groups and was maintained at 40-60 during surgery (Fig. 2d). TOF and airway peak pressure (Paw peak pressure) were recorded at $\mathrm{T} 1-\mathrm{T} 8$, because after $\mathrm{T} 8$, muscle relaxation subsided in most cases in the $20 \mu \mathrm{g} \cdot \mathrm{kg}^{-1}$ group, and participants were unable to tolerate the laryngeal mask. Additional doses of cis-atracurium were re-administered to patients after the T8 
Table 1 Population Demographics and Intraoperative and Preoperative Data

\begin{tabular}{|c|c|c|c|}
\hline Variable & $50 \mu \mathrm{g} \cdot \mathrm{kg}^{-1}$ & $30 \mu \mathrm{g} \cdot \mathrm{kg}^{-1}$ & $20 \mu \mathrm{g} \cdot \mathrm{kg}^{-1}$ \\
\hline Female sex & $1(25)$ & $1(10)$ & $2(33.3)$ \\
\hline Age (years) & $54.50(14.08)$ & $50.60(12.65)$ & $48.83(13.23)$ \\
\hline Weight (kg) & $77.00(12.36)$ & $76.90(5.28)$ & $75.67(14.90)$ \\
\hline Height $(\mathrm{cm})$ & $168.75(7.14)$ & $171.40(4.97)$ & $169.00(6.20)$ \\
\hline BMI & $26.90(2.37)$ & $26.21(2.02)$ & $26.32(3.93)$ \\
\hline Haemoglobin $\left(g \cdot \mathrm{L}^{-1}\right)$ & $137.5(19.16)$ & $140.30(9.59)$ & $138.67(25.45)$ \\
\hline Globin fraction of plasma protein $\left(\mathrm{g} \cdot \mathrm{L}^{-1}\right)$ & $30.98(4.89)$ & $24.21(3.45)$ & $23.87(5.61)$ \\
\hline Albumin fraction of plasma protein $\left(\mathrm{g} \cdot \mathrm{L}^{-1}\right)$ & $40.19(4.24)$ & $39.82(3.67)$ & $41.22(6.23)$ \\
\hline pH value & $7.37(0.04)$ & $7.38(0.03)$ & $7.39(0.03)$ \\
\hline Nasopharyngeal temperature $\left({ }^{\circ} \mathrm{C}\right)$ & $36.33(0.25)$ & $36.34(0.28)$ & $36.38(0.10)$ \\
\hline Operation duration (min) & $93(42.42)$ & $67.20(41.58)$ & $56.17(90.27)$ \\
\hline Anaesthesia duration (min) & $122.25(41.16)$ & $104.20(45.85)$ & $99.33(81.02)$ \\
\hline Blood loss (ml) & $141.03(13.52)$ & $139.01(10.18)$ & $138.89(20.11)$ \\
\hline \multicolumn{4}{|l|}{ Mallampati class } \\
\hline । & $0(0)$ & $1(10)$ & $1(16.67)$ \\
\hline$\|$ & $0(0)$ & $2(20)$ & $1(16.67)$ \\
\hline III & $4(100)$ & $7(70)$ & $3(50)$ \\
\hline IV & $0(0)$ & $0(0)$ & $1(16.67)$ \\
\hline \multicolumn{4}{|l|}{ ASA class } \\
\hline$\|$ & $2(50)$ & $2(20)$ & $1(16.67)$ \\
\hline III & $2(50)$ & $8(80)$ & $5(83.33)$ \\
\hline
\end{tabular}

ASA American Society of Anesthesiologists, BMI Body Mass Index

The numerical values (e.g., Mallampati class, ASA score, sex) are expressed as the number (\%) or number (proportion). All other values are expressed as the mean (SD)

${ }^{*} P<0.05 ; * * P<0.01$

timepoint. TOF and airway peak pressure (Paw peak pressure) were affected by re-administration of cis-atracurium; therefore, we did not include the TOF and airway peak pressure (Paw peak pressure) at T9 and T10 in the statistical analysis. The TOF value at T3 was significantly lower in the $50 \mu \mathrm{g} \cdot \mathrm{kg}^{-1}$ group than that in the $30 \mu \mathrm{g} \cdot \mathrm{kg}^{-1}$ group $(P=0.0226)$ (Fig. 2e). The TOF values in the $30 \mu \mathrm{g} \cdot \mathrm{kg}^{-1}$ group and in the $20 \mu \mathrm{g} \cdot \mathrm{kg}^{-1}$ group showed no difference at each timepoint, and the TOF values in the $50 \mu \mathrm{g} \cdot \mathrm{kg}^{-1}$ group and in the $20 \mu \mathrm{g} \cdot \mathrm{kg}^{-1}$ group also showed no difference at each timepoint (Fig. $2 \mathrm{e})$. The Paw pressure is indicative of airway protection and the supraglottic airway device placement condition. In this study, the airway peak pressure (i.e., mean Paw pressure) did not significantly differ between the $50 \mu \mathrm{g} \cdot \mathrm{kg}^{-1}$ group and the $30 \mu \mathrm{g} \cdot \mathrm{kg}^{-1}$ group at any timepoint. However, it was significantly higher at T8 in the $20 \mu \mathrm{g} \cdot \mathrm{kg}^{-1}$ group than that in the $30 \mu \mathrm{g} \cdot \mathrm{kg}^{-1}$ group $(P=$ 0.0423; Fig. 2f). There were no severe intraoperative haemodynamic changes or adverse reactions such as respiratory depression, nausea, or vomiting in any group.

\section{The ED50 and ED95 of cis-Atracurium}

In our patients, the ED50 (95\% CI) of cis-atracurium for laryngeal mask insertion, which was obtained using the up-and-down method, was $26.5 \mu \mathrm{g} \cdot \mathrm{kg}^{-1}$ (95\% CI, 23.629.8). We found that the laryngeal mask, based on a probit regression analysis, can be successfully inserted in $50 \%(95 \% \mathrm{CI})$ of anaesthetised adults at a cis-atracurium concentration of $26.5 \mu \mathrm{g} \cdot \mathrm{kg}^{-1}$ (95\% CI, $23.6 \mu \mathrm{g} \cdot \mathrm{kg}^{-1}$ $\left.29.8 \mu \mathrm{g} \cdot \mathrm{kg}^{-1}\right)$. The log dosage probit response curves for cis-atracurium for the insertion of the laryngeal mask (probability unit vs. concentration) are shown in Fig. 3. We generated the dose response curves and determined the effective doses of cis-atracurium required for the insertion of the laryngeal mask in adult patients (Fig. 3).

\section{Discussion}

In this study, we aimed to determine the optimal cisatracurium dosage for LMA insertion in anaesthetised adults using Dixon's up-and-down method and to determine the dose-response curves for LMA insertion in patients undergoing urinary surgery. We found that the ED50 of cis-atracurium for LMA insertion in the patients in this study was $26.5 \mu \mathrm{g} \cdot \mathrm{kg}^{-1}$. Based on our findings, we concluded that laryngeal mask insertion requires the same cis-atracurium dosage as tracheal intubation and is an important adjuvant to general anaesthesia. A previous study reported that the calculated ED50 value was $0.0262 \mathrm{mg} \cdot \mathrm{kg}^{-1}$ (95\% CI: $0.0258-0.0265$ ) 


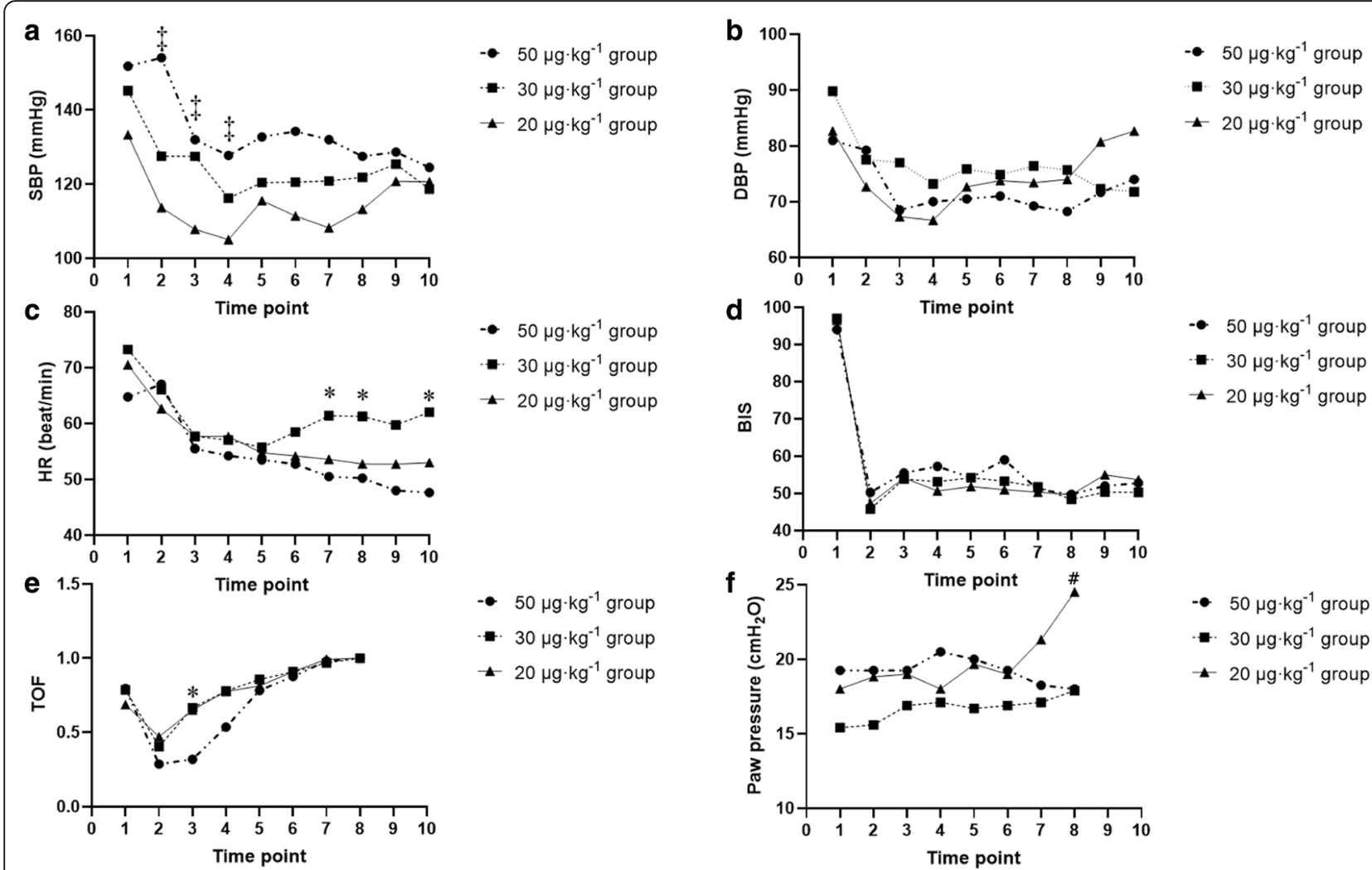

Fig. 2 Haemodynamic value fluctuation, train-of-four, Paw pressure and bispectral index value changes in three groups. Data are presented as mean \pm SD. * statistical significance between the $50 \mu \mathrm{g} \cdot \mathrm{kg}^{-1}$ group vs. $30 \mu \mathrm{g} \cdot \mathrm{kg}^{-1}$ group, $P<0.05$; $\neq$ statistically significant difference between the $50 \mu \mathrm{g} \cdot \mathrm{kg}^{-1}$ and $20 \mu \mathrm{g} \cdot \mathrm{kg}^{-1}$ groups, $P<0.05$; \# statistically significant difference between the $30 \mu \mathrm{g} \cdot \mathrm{kg}^{-1}$ and $20 \mu \mathrm{g} \cdot \mathrm{kg}^{-1}$ groups, $P<0.05$. There were ten timepoints: $T 1$ : administration of cis-atracurium, T2: 3 min after administration of cis-atracurium (LMA insertion), T3: 10 min after administration of cis-atracurium (i.e., beginning of the operation), T4: 20 min after administration of cis-atracurium, T5: 30 min after administration of cis-atracurium, T6: 40 min after administration of cis-atracurium, T7: 50 min after administration of cis-atracurium, T8: 60 min after administration of cis-atracurium, T9: 70 min after administration of cis-atracurium, and T10: $80 \mathrm{~min}$ after administration of cis-atracurium. Diastolic blood pressure (DBP) did not significantly differ among the groups. Systolic blood pressure (SBP) was significantly decreased in the $50 \mu \mathrm{g} \cdot \mathrm{kg}^{-1}$ group compared to that in the $20 \mu \mathrm{g} \cdot \mathrm{kg}^{-1} \mathrm{group}$ at T2, T3, and T4 ( $P=$ $0.0159, P=0.0233$, and $P=0.0428$, respectively). The heart rate (HR) significantly differed among the groups. The HR was significantly decreased in the $50 \mu \mathrm{g} \cdot \mathrm{kg}^{-1}$ group compared to that in the $20 \mu \mathrm{g} \cdot \mathrm{kg}^{-1}$ group at T7, T8, and T10 $(P=0.0482, P=0.0460$, and $P=0.0236$, respectively). The train-of-four [TOF] onset, the time to TOF ratio $=0$ TOF value). The TOF value at T3 was significantly lower in the $50 \mu \mathrm{g} \cdot \mathrm{kg}^{-1}$ group than in the $30 \mu \mathrm{g} \cdot \mathrm{kg}^{-1} \mathrm{group}(P=0.0326)$. The Paw pressure at each timepoint did not significantly differ between the $50 \mu \mathrm{g} \cdot \mathrm{kg}^{-1}$ and $30 \mu \mathrm{g} \cdot \mathrm{kg}^{-1}$ groups. However, the Paw pressure was significantly higher at T8 in the $30 \mu \mathrm{g} \cdot \mathrm{kg}^{-1}$ group than in the $20 \mu \mathrm{g} \cdot \mathrm{kg}^{-1}$ group $(P=0.0423)$

[22]. In another study, the ED50 (SD) and ED95 (SD) values of cis-atracurium were $0.021(0.04)$ and 0.051 (0.013) $\mathrm{mg} \cdot \mathrm{kg}^{-1}$, respectively, for tracheal intubation under total intravenous anaesthesia [23]. Tracheal intubation is required when the neuromuscular response is abolished, which is also an indication for laryngeal mask insertion. No consensus exists regarding the appropriate dose of muscle relaxant required for placing a laryngeal mask; the dose ranges from $1 / 10$ dose to the full dose for normal tracheal intubation [18]. One study [18] also demonstrated that the dose of muscle relaxants required for laryngeal mask placement was smaller than that of the muscle relaxants required for endotracheal intubation. This finding coincided with our results. The estimated ED50 for the total patient group was $35.11 \mu \mathrm{g} \cdot \mathrm{kg}^{-}$ ${ }^{1}$ [24]. The effective dose in our study differed from the
$48 \mu \mathrm{g} \cdot \mathrm{kg}^{-1}$ that was estimated as the ED95 of cis-atracurium by Belmont et al. [25] and differed from the ED50 and ED95 of $30 \mu \mathrm{g} \cdot \mathrm{kg}^{-1}$ and $53 \mu \mathrm{g} \cdot \mathrm{kg}^{-1}$, respectively, reported by Lepage et al. [26].

In our study, the SBP was significantly lower in the $20 \mu \mathrm{g} \cdot \mathrm{kg}^{-1}$ group at T2 (i.e., anaesthesia induction timepoint), T3, and T4, and was indistinguishable from the SBP in the $30 \mu \mathrm{g} \cdot \mathrm{kg}^{-1}$ group and the $50 \mu \mathrm{g} \cdot \mathrm{kg}^{-1}$ group. No significant difference in SBP was observed between the $50 \mu \mathrm{g} \cdot \mathrm{kg}^{-1}$ group and the $30 \mu \mathrm{g} \cdot \mathrm{kg}^{-1}$ group. However, the propensity to maintain the SBP at a relatively stable level at the preoperative stage was the same among the three groups.

Over $50 \%$ of the patients in the $20 \mu \mathrm{g} \cdot \mathrm{kg}^{-1}$ group had an unsatisfactory first response to laryngeal mask insertion. Placement of a laryngeal mask requires adequate 


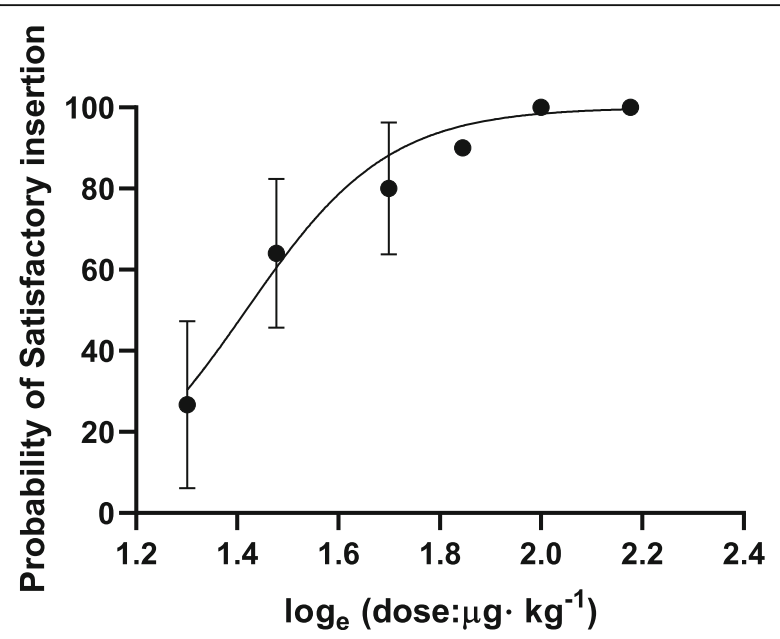

Fig. 3 Dose-response curve of cis-atracurium for the insertion of the laryngeal mask airway (probability unit vs. concentration). The median effective dose was 26.5 (95\% Cl: 33.6-29.8). Log dose/probit response curves of cis-atracurium for laryngeal mask airway insertion. The points along the lines represent the mean responses of subgroups of ten patients. Only four of six points are provided for the cis-atracurium group. In addition, 100\% of the patients who received the higher dose $\left(50 \mu \mathrm{g} \cdot \mathrm{kg}^{-1}\right)$ had a satisfactory laryngeal mask airway insertion response

anaesthesia depth and mouth opening. Therefore, administration of additional doses of propofol and sufentanil was needed to achieve satisfactory insertion. The combination of an appropriate dose of muscle relaxants can improve laryngeal mask placement without increasing the incidence of associated adverse reactions, while reducing the amount of propofol or sufentanil anaesthetics and reducing their inhibitory effect on the circulation [27]. Without the use of muscle relaxants, it is necessary to increase the depth of anaesthesia, which prolongs the time of the patient's recovery of consciousness.

Our results indicated that the HR was significantly decreased in the $50 \mu \mathrm{g} \cdot \mathrm{kg}^{-1}$ group compared to the $30 \mu \mathrm{g} \cdot \mathrm{kg}^{-1}$ group at T7, T8, and T10. This finding indirectly reflected a lower stress in the $50 \mu \mathrm{g} \cdot \mathrm{kg}^{-1}$ group compared to the $30 \mu \mathrm{g} \cdot \mathrm{kg}^{-1}$ group and the $20 \mu \mathrm{g} \cdot \mathrm{kg}^{-1}$ group. Cis-atracurium did not exert significant haemodynamic changes, even at different concentrations. However, the interaction among anaesthetic agents caused a statistically significant decline in some haemodynamic parameters at certain timepoints. However, this change was not a clinical effect and required no vasopressor agents. Using an appropriate NMBA did not affect the extubation time but reduced the stress reaction [28]. Cis-atracurium did not cause harmful autonomic nervous system effects and resulted in reduced secretion of histamine. Some investigators have demonstrated no cardiovascular system variations, even with histamine secretion, when administering a double dose of ED95 to patients with coronary artery disease [29, 30]. The pharmacodynamics of NMBAs are affected by several factors such as temperature [31, 32], use of inhalation agents, magnesium, local anaesthetics [33], antiepileptic drugs, age [34], weight [35], and plasma clearance and volume of distribution [30,36]. Our study revealed no difference among the three groups in terms of the ASA Physical Status, age, weight, height, and sex. The patients' body temperature in each group was maintained within the normal range. We restricted the use of inhalation anaesthesia throughout the operation.

Based on our findings, all three groups had recovered to the $100 \%$ TOF value by T6. The TOF value was significantly lower in the $50 \mu \mathrm{g} \cdot \mathrm{kg}^{-1}$ group than in the $30 \mu \mathrm{g} \cdot \mathrm{kg}^{-1}$ group. This finding indicates that the $50 \mu \mathrm{g} \cdot \mathrm{kg}^{-1}$ group had more efficient muscle relaxation. At the earliest timepoint, the TOF value did not significantly differ between the $30 \mu \mathrm{g} \cdot \mathrm{kg}^{-1}$ group and the $20 \mu \mathrm{g} \cdot \mathrm{kg}^{-1}$ group. The use of a relatively high dose of muscle relaxants will also prolong the extraction of the laryngeal mask due to the prolonged TOF recovery time. The administration of $200 \%$ of the ED95 values of cisatracurium, producing an onset duration of $5.2 \mathrm{~min}$, and the time to $25 \%$ of $\mathrm{T} 1$ recovery at $45 \mathrm{~min}$ have been reported [25, 36]. Tulgar [37] demonstrated that the use of subclinical doses of muscle relaxants does not affect the anaesthetic recovery time. In this study, the airway peak pressure (mean Paw pressure) was insignificantly different between the $50 \mu \mathrm{g} \cdot \mathrm{kg}^{-1}$ group and the $30 \mu \mathrm{g} \cdot \mathrm{kg}^{-1}$ group at each timepoint. However, the airway peak pressure at T8 was significantly higher in the $20 \mu \mathrm{g} \cdot \mathrm{kg}^{-1}$ group than in the $30 \mu \mathrm{g} \cdot \mathrm{kg}^{-1}$ group $(P=0.0423)$. Hemmerling [38] reported that a certain degree of muscle relaxation could prevent reduced sealing of the laryngeal mask owing to recovery of strength in the throat muscles.

Our study was limited in that we did not analyse subgroups of these patients. We plan to determine the differences in the ED50 between younger and elderly patients in our future study because reactions and pharmacokinetics differ between young and elderly patients. We also plan to analyse the differences based on sex in the future. Our research provides information for anaesthesiologists, which could help them improve general anaesthesia induction and LMA insertion in patients undergoing minor surgeries.

\section{Conclusion}

In this study, the ED50 of cis-atracurium for effective muscle relaxation in urinary surgery for LMA insertion was $26.5 \mu \mathrm{g} \cdot \mathrm{kg}^{-1}$. 


\section{Appendix}

\section{The formula for ED50}

The numbers of satisfactory ( $r$ ) and unsatisfactory cases (s) of laryngeal mask insertion under different doses of cis-atracurium were determined. The logarithm (x) of each dose, total number of patients (n), satisfaction rate of laryngeal mask insertion (p), and difference (I) between the logarithms of two adjacent doses were calculated. The ED50 and its 95\% CI were calculated using the following formula for half-dose sequential calculation:

$$
P=\mathrm{r} /(\mathrm{r}+\mathrm{s})
$$

Pair value $\operatorname{lgED} 50$ of ED50 $=\sigma \mathrm{NX} / \sigma \mathrm{n}$. Standard error of $\operatorname{lgED} 50(\mathrm{SlgED} 50)=\mathrm{I} \sqrt{ } \sigma[\mathrm{p}(1-\mathrm{p}) /(\mathrm{n}-1)]$ with $95 \%$ CI of ED50 pairs of values (IED 50-1.96 SlgED50; $\operatorname{lgED} 50+1.96$ SlgED50.

\section{Supplementary information}

Supplementary information accompanies this paper at https://doi.org/10. 1186/s12871-020-00982-3.

Additional file 1: Table S1. Findings Regarding Resistance to Mouth Opening, Resistance to Insertion, Cough, Swallowing, Laryngospasm/ Airway Obstruction, and Head and Body Movement.

\section{Abbreviations}

ASA: American Society of Anesthesiologists; BIS: Bispectral index; BMI: Body Mass Index; DBP: Diastolic blood pressure; ED50: The median effective dose; HR: Heart rate; IRB: Institutional review board; LMA: Laryngeal mask airway; NMBAs: Neuromuscular blocking agents; SBP: The systolic blood pressure; $\mathrm{SpO}_{2}$ : Pulse oxygen saturation; STROBE: Observational Studies in Epidemiology; TOF: Train-of-four

\section{Acknowledgements}

This research was supported by the National Natural Science Foundation of China and the department of Urinary surgery at Xuanwu Hospital. The authors thank Jiangtao Wu, Hao Yan, and Tongwen Ou for performing the operation and assisting in manuscript preparation.

\section{Authors' contributions}

XW; Contribution: contributed to data acquisition and analysis, and drafted manuscript. $\mathrm{KH}$; Contribution: contributed to trial conduction, and helped prepare the cis-atracurium concentrations. HY; Contribution: contributed to performing the operation, writing manuscript and funding support. DY; Contribution: contributed to trial conduction, and helped place a flexible LMA of the appropriate type. JX; Contribution: contributed to trial conduction, and helped evaluate the patients' responses and was blinded to the cis-atracurium concentrations. FL; Contribution: contributed to substantively revised the manuscript. YL; Contribution: contributed to interpretation of data and helped to revise the manuscript. TW; Contribution: contributed to the design of the research and agreed to be accountable for all aspects of this work. All authors read and approved the final manuscript version.

\section{Funding}

The National Natural Science Foundation of China (No. 81401084); Beijing Municipal commission of Health and Family Planning (No. PXM2017_026283_000002); Beijing Municipal Administration of Hospitals Clinical Medicine Development of Special Funding Support (ZYLX201813; No. 303-01-005-0159); Beijing Municipal Administration of Hospitals Clinical Medicine Development of Special Funding Support (XMLX201829; No. 30301-005-0162) in part funded this work in part.

\section{Availability of data and materials}

The raw data of this study are available from the corresponding author on reasonable request.

\section{Ethics approval and consent to participate}

This prospective observational study was approved by the local ethics committee (Capital Medical University Institutional Review Board, China, December 8, 2017; IRB no.: 2017-D136). Written informed consent was obtained from all patients participating in the trial. The trial was registered with http://www.ClinicalTrials.gov (NCT-03668262; date of registration, September $11,2018)$. Our methodology followed the international guidelines for observational studies.

\section{Consent for publication}

Not applicable.

\section{Competing interests}

The authors declare that they have no competing interests.

\section{Author details}

${ }^{1}$ Department of Anesthesiology, Xuanwu Hospital, Capital Medical University, Beijing 100053, China. ${ }^{2}$ Institute of Geriatrics, Beijing 100053, China. ${ }^{3}$ National Clinical Research Center for Geriatric Disorders, Beijing 100053, China. ${ }^{4}$ Department of Urinary surgery, Xuanwu Hospital, Capital Medical University, Beijing 100053, China.

Received: 7 September 2019 Accepted: 9 March 2020

Published online: 19 March 2020

\section{References}

1. Cattano D, Van Zundert TCRV, Wojtczak J. Laryngeal mask airway and the enigma of anatomical sizing. J Clin Monit Comput. 2019;33(5):757-8.

2. Hohlrieder M, Brimacombe J, von Goedecke A, et al. Postoperative nausea, vomiting, airway morbidity, and analgesic requirements are lower for the ProSeal laryngeal mask airway than the tracheal tube in females undergoing breast and gynaecological surgery. Br J Anaesth. 2007:99(4): 576-80

3. Erhan E, Ugur G, Anadolu O, et al. General anaesthesia or spinal anaesthesia for outpatient urological surgery. Eur J Anaesthesiol. 2003;20(8):647-52.

4. Baker AR, Baker AB. Anaesthesia for endoscopic sinus surgery. Acta Anaesthesiol Scand. 2010;54(7):795-803

5. Hu LQ, Leavitt OS, Malwitz C, et al. Comparison of laryngeal mask airway insertion methods, including the external larynx lift with pre-inflated cuff, on postoperative pharyngolaryngeal complications: a randomized clinical trial. Eur J Anaesthesiol. 2017;34(7):448-55.

6. Scanlon P, Carey M, Power M, et al. Patient response to laryngeal mask insertion after induction of anaesthesia with propofol or thiopentone. Can J Anaesth. 1993:40(9):816-8.

7. Chandra S, Pryambodho P, Melati AC, et al. Comparison Between Lidocaine Inhalation and Intravenous Dexamethasone in Reducing Postoperative Sore Throat Frequency After Laryngeal Mask Insertion. Anesth Pain Med. 2018; 8(5):e82131.

8. Eichelsbacher $\mathrm{C}$, Ilper $\mathrm{H}$, Noppens $\mathrm{R}$, et al. Rapid sequence induction and intubation in patients with risk of aspiration: recommendations for action for practical management of anesthesia. Anaesthesist. 2018;67(8):568-83.

9. Michel J, Hofbeck M, Gerbig I, et al. Nurse-driven analgesia and sedation in pediatric patients with univentricular hearts requiring extracorporeal life support after first-stage palliation surgery: a pilot study. Paediatr Anaesth. 2017;27(12):1261-70

10. Nasseri K. Effect of low-dose Atracurium on laryngeal mask airway insertion conditions: a randomized double-blind clinical trial. Adv Biomed Res. 2017; 6(1):119.

11. Ortiz JR, Percaz JA, Carrascosa F. Cisatracurium. Rev Esp Anestesiol Reanim. 1998;45(6):242-7.

12. Fuchs-Buder T. New muscle relaxants. Update on mivacurium, rocuronium and cis-atracurium. Anaesthesist. 1997;46(4):350-9.

13. Diefenbach C, Buzello W. New muscle relaxants. Anasthesiol Intensivmed Notfallmed Schmerzther. 1996;31(1):2-8.

14. Savarese JJ, Wastila WB. The future of the benzylisoquinolinium relaxants. Acta Anaesthesiol Scand Suppl. 1995;106:91-3. 
15. Konrad FM, Unertl KE, Schroeder TH. Mastocytosis. A challenge in anaesthesiology. Anaesthesist. 2009;58(12):1239-43.

16. Kim KS, Chun YS, Chon SU, et al. Neuromuscular interaction between cisatracurium and mivacurium, atracurium, vecuronium or rocuronium administered in combination. Anaesthesia. 1998;53(9):872-8.

17. Bergeron L, Bevan DR, Berrill A, et al. Concentration-effect relationship of cisatracurium at three different dose levels in the anesthetized patient. Anesthesiology. 2001;95:314-23.

18. Naguib M, Samarkandi AH, Ammar A, et al. Comparative clinical pharmacology of rocuronium, cisatracurium, and their combination. Anesthesiology. 1998;89(5):1116-24.

19. Kim JH, Lee YC, Lee SI, et al. Effective doses of cisatracurium in the adult and the elderly. Korean J Anesthesiol. 2016;69(5):453-9.

20. Dixon WJ. Staircase bioassay: the up-and-down method. Neurosci Biobehav Rev. 1991;15(1):47-50.

21. Sivalingham P, Kandasamy R, Madhaven G, et al. Conditions for laryngeal mask insertion: a comparison of propofol versus sevoflurane with or without alfentanil. Anaesthesia. 1999;54:271-6.

22. Wulf $\mathrm{H}$, Kahl M, Ledowski T. Augmentation of the neuromuscular blocking effects of cisatracurium during desflurane, sevoflurane, isoflurane or total i.v. anaesthesia. Br J Anaesth. 1998;80(3):308-12.

23. Park WY, Choi JC, Yun HJ, et al. Optimal dose of combined rocuronium and cisatracurium during minor surgery: a randomized trial. Medicine (Baltimore). 2018:97(10):e9779.

24. Belmont MR, Lien CA, Quessy S, et al. The clinical neuromuscular pharmacology of 51W89 in patients receiving nitrous oxide/opioid/ barbiturate anesthesia. Anesthesiology. 1995;82:1139-45.

25. Lepage JY, Malinovsky JM, Malinge M, et al. Pharmacodynamic doseresponse and safety study of cisatracurium (51W89) in adult surgical patients during N2O-O2-opioid anesthesia. Anesth Analg. 1996;83:823-9.

26. George LR, Sahajanandan R, Ninan S. Low-dose succinylcholine to facilitate laryngeal mask airway insertion: a comparison of two doses. Anesth Essays Res. 2017;11(4):1051-6.

27. Smith SE, Hamblin SE, Dennis BM. Effect of neuromuscular blocking agents on sedation requirements in trauma patients with an open abdomen. Pharmacotherapy. 2019;39(3):271-9.

28. Naguib M, Lien CA, Meistelman C. Pharmacology of muscle relaxants and their antagonists. In: Miller RD, editor. Miller's Anesthesia. 8th ed. Philadelphia: Churchill Livingstone/Elsevier; 2015. p. 958-94.

29. Kisor DF, Schmith VD. Clinical pharmacokinetics of cisatracurium besilate. Clin Pharmacokinet. 1999;36:27-40.

30. Sorooshian SS, Stafford MA, Eastwood NB, et al. Pharmacokinetics and pharmacodynamics of cisatracurium in young and elderly adult patients. Anesthesiology. 1996;84:1083-91.

31. Amin AM, Mohammad MY, Ibrahim MF. Comparative study of neuromuscular blocking and hemodynamic effects of rocuronium and cisatracurium under sevoflurane or total intravenous anesthesia. Middle East J Anaesthesiol. 2009:20(1):39-51.

32. Kim YB, Sung TY, Yang HS. Factors that affect the onset of action ofnondepolarizing neuromuscular blocking agents. Korean J Anesthesiol. 2017;70:500-10.

33. Ornstein E, Lien CA, Matteo RS, et al. Pharmacodynamics and pharmacokinetics of cisatracurium in geriatric surgical patients. Anesthesiology. 1996;84:520-5.

34. Leykin $Y$, Pellis T, Lucca M, et al. The pharmacodynamic effects of rocuronium when dosed according to real body weight or ideal body weight in morbidly obese patients. Anesth Analg. 2004;99:1086-9.

35. Arain SR, Kern S, Ficke DJ, et al. Variability of duration of action of neuromuscular-blocking drugs in elderly patients. Acta Anaesthesiol Scand. 2005:49:312-5

36. Naguib M. Neuromuscular effects of rocuronium bromide and mivacurium chloride administered alone and in combination. Anesthesiology. 1994;81:388-95.

37. Tulgar S, Boga I, Cakiroglu B, et al. Short-lasting pediatric laparoscopic surgery: are muscle relaxants necessary? Endotracheal intubation vs. laryngeal mask airway. J Pediatr Surg. 2017;52(11):1705-10.

38. Hemmerling TM, Michaud G, Deschamps S, et al. Patients who sing need to be relaxed'--neuromuscular blockade as a solution for air-leaking during intermittent positive pressure ventilation using LMA. Can J Anaesth. 2005;52(5):549.

\section{Publisher's Note}

Springer Nature remains neutral with regard to jurisdictional claims in published maps and institutional affiliations.

\section{Ready to submit your research? Choose BMC and benefit from:}

- fast, convenient online submission

- thorough peer review by experienced researchers in your field

- rapid publication on acceptance

- support for research data, including large and complex data types

- gold Open Access which fosters wider collaboration and increased citations

- maximum visibility for your research: over $100 \mathrm{M}$ website views per year

At BMC, research is always in progress.

Learn more biomedcentral.com/submissions 